Rev. Adm. Saúde - Vol. 18, № 70, jan. - mar. 2018

http://dx.doi.org/10.23973/ras.70.92

ARTIGO ORIGINAL

\title{
Avaliação dos cuidados de enfermagem com o cateter venoso central em uma unidade de terapia intensiva adulto e pediátrica
}

Evaluation of nursing care with the central venous catheter in a unit of intensive adult and pediatric therapy

\section{Fernanda Coura Sousa ${ }^{1}$, Juliana Cristina Pereira ${ }^{2}$, Diana de Andrade Rezende $^{3}$, Chen Laura ${ }^{4}$}

1. Enfermeira, especialista em terapia intensiva. Residente de enfermagem em urgência e trauma pelo Hospital João XXIII. Belo Horizonte MG

2. Enfermeira, mestre em enfermagem, especialista em vigilância e controle das infecções. Preceptora do Programa de Residência Multiprofissional em Saúde em Urgência e Emergência do Hospital João XXIII. Belo Horizonte MG

3. Enfermeira, especialista em assistência hospitalar ao neonato e em terapia intensiva e emergências para enfermeiros. Preceptora do Programa de Residência Multiprofissional em Saúde em Urgência e Emergência do Hospital João XXIII. Belo Horizonte MG

4. Enfermeira. Residente de enfermagem em urgência e trauma pelo Hospital João XXIII. Belo Horizonte MG

\section{RESUMO}

Objetivos: avaliar os cuidados de enfermagem relacionados ao cateter venoso central (CVC) em uma Unidade de Terapia Intensiva adulto e pediátrica, comparar a conduta ao protocolo padronizado na instituição e analisar os resultados baseando-se no manual da Agência Nacional de Vigilância de 2017. Metodologia: trata-se de uma auditoria clínica realizada em um hospital público de Minas Gerais. Foram selecionados os pacientes portadores de CVC, internados em leito par no período de junho e julho de 2017 no setor. Os dados foram coletados através do preenchimento de instrumento elaborado pela autora para a auditoria, através de observação direta da troca de curativo do CVC. Resultados: foram avaliadas 15 trocas de curativo, realizadas por 6 enfermeiros. As principais informações extraídas do estudo foram 
sistematizadas em quatro tópicos: dados relacionados ao paciente, ao cateter venoso central, aos materiais utilizados na realização do curativo e aos cuidados de enfermagem. Conclusão: a auditoria no cuidado de enfermagem na troca de curativo de CVC favoreceu um processo educativo entre os enfermeiros, contribuiu para identificar estratégias para melhorar a assistência e propôs uma atualização do protocolo da instituição

Palavras-chave: cateteres venosos centrais, infecções relacionadas a cateter, enfermagem baseada em evidências, controle de infecção.

\section{ABSTRACT}

Objectives: To evaluate nursing care related to the central venous catheter (CVC) in an adult and pediatric Intensive Care Unit, to compare the conduct to the standardized protocol in the institution and to analyze the results based on the Agência Nacional de Vigilância Sanitária's manual of 2017. Methodology: This is a clinical audit performed at a public hospital in Minas Gerais. We selected patients with CVC who were hospitalized in a couple bed in the period of June and July of 2017 in the sector. The data were collected through the completion of an instrument prepared for the audit, through direct observation of the CVC dressing exchange. Results: 15 dressing changes were performed, performed by 6 nurses. The main information extracted from the study was systematized in four categories: data related to the patient, central venous catheter, materials used to perform the dressing and nursing care. Conclusion: the nursing care audit in the exchange of CVC dressing favored an educational process among the nurses, contributed to identify strategies to improve care and proposed an update of the institution's protocol

Keywords: central venous catheters, catheter-related infections, evidencebased nursing, infection control.

\section{INTRODUÇÃO}

As infecções relacionadas à assistência à saúde (IRAS) são definidas como condições sistêmicas ou localizadas resultantes de reações adversas à presença de agentes infecciosos ou suas toxinas que não estavam presentes em um período de incubação à admissão do paciente no ambiente assistencial ${ }^{1}$.

Este tipo de infecção representa uma causa importante de morbidade e mortalidade em adultos e crianças gravemente enfermos, significando aumento do tempo de internação, maior afastamento do paciente de seus cotidianos, 
além de gerar mais custos ao hospital devido à utilização de medicamentos e à realização de mais exames laboratoriais e de imagem ${ }^{2}$. Os fatores de risco para IRAS incluem as características do paciente, os procedimentos invasivos aos quais ele foi exposto, o estado imunológico comprometido, a infusão de antibióticos e medicamentos, hemoderivados, nutrição parenteral e as especificidades do próprio acesso vascular. Estima-se que cerca de $60 \%$ das infecções sejam associadas a algum dispositivo intravascular ${ }^{3}$.

A infecção de corrente sanguínea (ICS) relacionada a cateteres centrais (ICSRC) também está associada a desfechos desfavoráveis em saúde ${ }^{4}$. Em um estudo realizado em São Paulo², das 1390 ICS analisadas, 68,3\% dos episódios de infecção foram associados ao uso de dispositivos intravasculares - cateter venoso central (CVC) $(66,6 \%)$ e cateter venoso periférico $(1,7 \%)$, com a taxa de óbito de $21,9 \%$. Além deste, um estudo internacional demonstrou que, dos 340 pacientes portadores de CVC, 15,6\% desenvolveu ICSRC e, dentro destes, $11,3 \%$ vieram a óbito ${ }^{5}$.

A ICSRC é definida quando não existe um foco infeccioso primário aparente e quando as hemoculturas (do sangue periférico e da ponta do cateter), colhidas após 48 horas de internação, apresentam crescimento do mesmo agente infeccioso isolado em cultura de ponta de cateter ou em sangue refluído de cateter, com mesmo perfil fenotípico ${ }^{4}$.

Os cateteres venosos centrais (CVC) são acessos vasculares utilizados para infusão de medicações, soluções endovenosas, hemoderivados e quimioterápicos em pacientes com limitação de acesso venoso periférico e, ainda, para nutrição parenteral prolongada, monitorização hemodinâmica invasiva da pressão sanguínea arterial, pressão venosa central, pressão da artéria pulmonar, medição de débito cardíaco e acesso para hemodiálise ${ }^{6-7}$. Embora o CVC forneça acesso vascular seguro, as práticas inadequadas em seu manuseio podem acarretar em maior risco de diversas complicações para os pacientes incluindo a ICSRC ${ }^{8-10}$.

Nesse contexto, destaca-se a equipe de enfermagem, que representa os profissionais que estão mais envolvidos no momento de implantação do CVC, auxiliando a equipe médica e em seu manuseio ${ }^{11}$. $O$ enfermeiro possui papel essencial na prevenção da ICSRC, pois a manipulação do dispositivo, principalmente a troca de curativo, é de responsabilidade deste profissional, sendo responsável também pela identificação e notificação dos casos de infecção associada aos cuidados em saúde e maior possibilidade de atuação na profilaxia e controle das IRAS ${ }^{11}$.

A problemática do estudo se dá pelo fato de que a ICSRC apresenta um caráter que na maioria das vezes pode ser prevenido, tendo em vista que desde ações simples, como a lavagem das mãos, até ações mais complexas como a esterilização de materiais para punção do CVC são imprescindíveis e eficazes na prevenção desta infecção ${ }^{12}$. Assim, a avaliação dos cuidados de enfermagem relacionados a troca de curativo do CVC pode subsidiar a tomada de decisões sobre mudanças e melhorias a serem implementadas. 
Diante da importância do cenário descrito, propõe-se a realização deste estudo cujo objetivo é avaliar os cuidados de enfermagem relacionados ao CVC nas unidades de terapia intensiva (UTI) adulto e pediátrica, de um hospital público de alta complexidade de Minas Gerais, comparar a conduta ao protocolo padronizado na instituição e analisar os resultados baseando-se no manual da Agência Nacional de Vigilância Sanitária (ANVISA) intitulada "Medidas de Prevenção de Infecção Relacionada à Assistência à Saúde" de 2017.

\section{METODOLOGIA}

Realizou-se um estudo do tipo auditoria clínica, sistema de revisão e controle, para verificar a adequação, a qualidade e a efetividade dos procedimentos e serviços de saúde disponibilizados à população ${ }^{13}$. Este tipo de estudo tem como principal função apontar sugestões e soluções a partir de problemas e falhas identificados, o que lhe confere um caráter educacional, além de informar à administração hospitalar sobre a utilização dos protocolos já instituídos na instituição ${ }^{14-15}$.

O estudo foi realizado na Unidade de Terapia Intensiva (UTI) adulto e pediátrica de um Hospital Público de alta complexidade de Minas Gerais.

Os participantes do estudo foram selecionados da seguinte forma: ser portador de CVC, estar internado em leito número par na UTI (os pacientes internados em leitos pares tomam banho durante o plantão diurno e tem os curativos de CVC trocados durante o dia) e estar internado no período de junho e julho de 2017 no setor.

Os preceitos éticos descritos na Resolução № 466/2012 do Conselho Nacional de Saúde foram respeitados e, portanto, as coordenações de enfermagem das UTI Adulto e Pediátrica assinaram o termo de consentimento livre esclarecido previamente. A pesquisa foi aprovada pelo Comitê de Ética e Pesquisa da Fundação Hospitalar de Minas Gerais (CEP/FHEMIG), sob o parecer de número 70798117.5.0000.5119.

Inicialmente ocorreu a análise do protocolo padronizado na instituição e realizou-se uma busca na literatura sobre os cuidados de enfermagem ao paciente portador de CVC. Posteriormente deu-se a criação do instrumento para realização da auditoria clínica. Foi realizado um teste piloto com cinco indivíduos para verificar a confiabilidade das variáveis. Ressalta-se que os participantes do teste relatado não entraram no estudo.

O instrumento elaborado possui quatro tópicos que foram preenchidos pelo pesquisador. O primeira refere-se ao paciente: idade, número de registro, data de admissão, diagnóstico de internação e local da avaliação (UTI pediátrica ou adulto). O segundo refere-se ao cateter venoso central: sítio de implantação do CVC, data da punção, categoria profissional do responsável pela realização do curativo e data do último curativo. O terceiro é referente aos materiais utilizados na realização do curativo: equipamento de proteção individual (EPI) (luvas de procedimento, luvas estéreis, máscara, óculos e gorro) e o material utilizado na 
confecção do curativo (gaze estéril, gaze não estéril, gluconato de clorexidina degermante a $2 \%$, gluconato de clorexidina alcoólica $0,5 \%$, soro fisiológico 0,9\% $10 \mathrm{ml}$, micropore/esparadrapo, kit curativo e cobertura estéril semipermeável de poliuretano). O quarto tópico refere-se os cuidados de enfermagem com o CVC e ao curativo (higienização das mãos préprocedimento, retirada do curativo com luvas de procedimento, retirada do curativo sem tração do cateter, cateter exteriorizado, cateter bem fixado, presença de sinais flogísticos, limpeza da inserção do cateter com gluconato de clorexidina degermante $2 \%$, limpeza da inserção do cateter com gluconato de clorexidina alcoólica $0,5 \%$ durante 30 segundos, limpeza seguindo direção cateter-extremidade, gaze trocada de lado a cada pincelada, curativo identificado corretamente com data da punção e data da troca do curativo, higienização das mãos pós-procedimento, evolução do enfermeiro sobre o sítio de inserção e sinais flogísticos).

Durante a execução do estudo, as trocas dos curativos de CVC foram avaliadas através de observação direta pelos pesquisadores e, imediatamente após a observação, foi preenchido o formulário de coleta de dados, sendo um formulário para cada curativo observado. Os prontuários dos pacientes foram acessados através de um sistema de informação integrado em rede utilizado na instituição no intuito de verificar as anotações quanto à troca de curativo, características do sítio de inserção e sinais flogísticos descritos na evolução do enfermeiro responsável pelo curativo.

Os dados foram analisados com auxílio do Microsoft Excel versão 2007.

As evidências encontradas no estudo foram categorizadas de acordo com as recomendações da Task Force for Periodics Health Examination ${ }^{16} \mathrm{e}$ do Grading of Recommendations Assessment, Development and Evaluation system (GRADE) ${ }^{17}$ :

- Categoria I: Alta - A evidência é classificada como de alta qualidade quando existe ampla gama de estudos sem grandes limitações, com pouca variação entre os estudos e com estreito intervalo de confiança.

- Categoria II: Moderada - A evidência é classificada como de moderada qualidade quando há poucos estudos e alguns apresentam limitações sem grandes falhas, com alguma variação entre os estudos ou amplo intervalo de confiança.

- Categoria III: Baixa - A evidência é classificada como de baixa qualidade quando os estudos apresentam falhas significativas, há importante variação entre eles, o intervalo de confiança é muito amplo ou não existem estudos bem desenhados, apenas consenso de especialistas.

Como subsídio de melhoria, foi realizado uma reunião com os enfermeiros do setor no intuito de propor uma análise reflexiva dos resultados da pesquisa e fornecer dados para definição de metas e estratégias para resolução dos problemas levantados. 


\section{RESULTADOS}

Foram avaliadas 15 trocas de curativos de pacientes internados na UTI adulto, realizadas por 6 enfermeiros. Vale ressaltar que, devido à pesquisa incluir somente os pacientes de banho diurno, o número de curativos observados foi suficiente para a realização da pesquisa, pois analisou a forma como a troca de curativos de CVC era realizada, e, para a realização de uma auditoria, não há um número mínimo necessário. Não houve crianças portadoras de CVC internadas na UTI pediátrica no tempo determinado da pesquisa, inviabilizando a pesquisa nesse setor.

Quanto aos dados de identificação dos pacientes selecionados, 11 (73,3\%) eram do gênero masculino e $4(26,7 \%)$ do gênero feminino e a idade média dos indivíduos foi 49 anos, variando de 17 a 80 anos. Em relação aos diagnósticos de internação, 9 (60\%) possuíam diagnósticos clínicos (doença pulmonar obstrutiva crônica, hemorragia subaracnóidea espontânea, hematêmese, encefalite viral, epilepsia não especificada, septicemia não especificada e transtorno mental não especificado) e $6(40 \%)$ possuíam diagnósticos relacionados ao trauma (fraturas múltiplas envolvendo ossos da face e do crânio e traumatismos múltiplos não especificados). Em relação ao tópico Cateter Venoso Central, pode-se observar a distribuição por gênero na Tabela 1.

Tabela 1. Distribuição por gênero dos sítios de inserção dos CVC na UTI adulto.

\begin{tabular}{lrrrr}
\hline Local de punção & Feminino $(\mathrm{n})$ & Masculino $(\mathrm{n})$ & Total $(\mathrm{n})$ & $(\%)$ \\
\hline Femoral & 2 & 4 & 6 & 40,0 \\
Jugular & 1 & 4 & 5 & 33,3 \\
Subclávia & 1 & 3 & 4 & 26,6 \\
\hline Total & 4 & 11 & 15 & 100,0 \\
\hline
\end{tabular}

Quanto à utilização dos EPI (luvas, máscara, óculos e gorro) a Tabela 2 demonstra que $1(6,7 \%)$ enfermeiro não utilizou luva estéril durante o procedimento, 4 (26,7\%) não usaram máscara e 14(93,4\%) não usaram óculos.

Tabela 2. Utilização do uso de EPI durante a realização dos curativos de CVC na UTI adulto.

\begin{tabular}{lrrrr}
\hline EPI & Sim & \multicolumn{3}{c}{ Não } \\
& $(\mathrm{n})$ & $(\%)$ & $(\mathrm{n})$ & $(\%)$ \\
\hline Luvas de procedimento & 15 & 100,0 & 0 & 0,0 \\
Luva estéril & 14 & 93,3 & 1 & 6,7
\end{tabular}




\begin{tabular}{lrrrr} 
Máscara & 11 & 73,3 & 4 & 26,7 \\
Óculos & 1 & 6,6 & 14 & 93,4 \\
Gorro & 12 & 80,0 & 3 & 20,0 \\
\hline
\end{tabular}

Todos os curativos observados foram realizados pelo enfermeiro, 6 (40\%) foram realizados com gaze estéril e fita adesiva microporosa não estéril e 9 $(60 \%)$ com filmepoliuretano estéril.

De todos os curativos, nenhum possuía a data de punção do CVC descrita e 5 $(33,3 \%)$ não possuíam a data de realização do curativo anterior.

No que se refere às substâncias utilizadas na limpeza do CVC, o uso de gluconato de clorexidina degermante $2 \%$ foi utilizado em $100 \%$ dos curativos. Já o gluconato de clorexidina alcoólico $0,5 \%$ foi utilizado em $2(13,3 \%)$ curativos. Este fato pode ser justificado mediante indisponibilidade do material na instituição.

No tópico Cuidados de Enfermagem, conforme Tabela 3, é possível observar a baixa adesão na higienização das mãos por parte dos enfermeiros préprocedimento, tanto no uso de água e sabão quanto no uso de álcool $70 \%$ : em $6(40 \%)$ curativos os enfermeiros não higienizaram as mãos pré-procedimento e em $11(73,3 \%)$ higienizaram após o procedimento. Também é possível perceber que a técnica asséptica correta não foi realizada por nenhum enfermeiro.

Tabela 3. Distribuição dos procedimentos de enfermagem na realização dos curativos de CVC na UTI adulto, Belo Horizonte, Minas Gerais, 2017.

\begin{tabular}{|c|c|c|c|c|}
\hline Procedimento & $\begin{array}{r}\text { Sim } \\
(\mathrm{n})\end{array}$ & $(\%)$ & $\begin{array}{r}\text { Não } \\
(\mathrm{n}) \\
\end{array}$ & $(\%)$ \\
\hline $\begin{array}{l}\text { Higienização das mãos pré- } \\
\text { procedimento }\end{array}$ & 6 & 40,0 & 9 & 60,0 \\
\hline $\begin{array}{l}\text { Higienização das mãos pós- } \\
\text { procedimento }\end{array}$ & 11 & 73,3 & 4 & 26,7 \\
\hline $\begin{array}{l}\text { Limpeza da inserção com clorexidina } \\
\text { degermante }\end{array}$ & 15 & 100,0 & 0 & 100,0 \\
\hline $\begin{array}{l}\text { Limpeza da inserção do cateter com } \\
\text { clorexidina alcoólica durante } 30 \\
\text { segundos }\end{array}$ & 0 & 0,0 & 15 & 100,0 \\
\hline Gaze trocada de lado a cada pincelada & 0 & 0,0 & 15 & 100,0 \\
\hline $\begin{array}{l}\text { Limpeza seguindo direção cateter } \\
\text { extremidade }\end{array}$ & 0 & 0,0 & 15 & 100,0 \\
\hline $\begin{array}{l}\text { Retirada do curativo sem tração do } \\
\text { cateter }\end{array}$ & 14 & 93,3 & 1 & 6,7 \\
\hline
\end{tabular}


De todos os cateteres avaliados, 3(20\%) estavam exteriorizados, 12 (80\%) estavam bem fixados e nenhum apresentava sinais flogísticos.

Ao acessar o prontuário eletrônico dos pacientes constatou-se que 4 (26,6\%) curativos foram evoluídos pelos enfermeiros e havia informações sobre o sítio de inserção do cateter e sinais flogísticos.

\section{DISCUSSÃO}

A ausência de crianças portadoras de CVC na UTI pediátrica no tempo do estudo não demonstra a realidade desta e de outras UTI. Estudo ${ }^{18}$ encontrou 401 crianças internadas, sendo destas 344 portadoras de CVC, durante um ano de coleta. Ressalta-se que o tempo de coleta desta pesquisa foi um fator limitador para a obtenção de resultados.

No que concerne aos dados de identificação, estudo ${ }^{19}$ encontrou que $36,3 \%$ dos pacientes eram do gênero feminino e $56,3 \%$ do masculino, o que também foi observado nesta pesquisa com o predomínio do gênero masculino. A média de idade encontrada tanto nesta pesquisa quanto no estudo referido foram $49 \mathrm{e}$ 56 anos, respectivamente. Esse estudo não exibe diferença estatisticamente significativa na incidência de infecção da corrente sanguínea. Não existem evidências científicas disponíveis sobre a relação gênero e ICSRC e não foi encontrada uma relação entre diagnóstico e ICSRC.

A escolha por um CVC de curta permanência, como o observado nesta pesquisa, deve acontecer através de indicação precisa para evitar seu uso desnecessário. Importante ressaltar que se há a proposta de manter o CVC por mais de 21 dias, deve-se preferir cateteres de média a longa permanência no momento da punção ${ }^{20}$.

Contrariando outros estudos ${ }^{20-22}$, esta pesquisa encontrou predomínio na taxa de punção em veia femoral em detrimento de outros sítios. No entanto, sabe-se que a cateterização femoral associa-se a maior frequência de complicações mecânicas (12,8 a 19,4\%), maior risco de desenvolvimento de ICSRC (I) ${ }^{20-21}$ e complicações trombóticas ${ }^{22}$, sendo as veias subclávia e jugular as de primeira escolha caso não haja contraindicações ${ }^{21-22}$. As taxas de complicações descritas para punções de veias subclávia e jugular interna são semelhantes entre si (6,2 a 10,7\% e 6,3 a 11,8\%, respectivamente). A subclávia apresenta maior risco de pneumotórax e hemotórax, e a jugular interna maior incidência de hematomas e punções arteriais ${ }^{23}$.

Estudos ${ }^{20,24-25}$ recomendam que a manipulação do CVC deva seguir as recomendações de assepsia, utilizando luva não estéril e estéril, gorro, máscara, óculos e capote (II). O capote não foi inserido nas estatísticas desta pesquisa por não estar no protocolo da instituição, porém o uso adequado deveria ser levado em conta devido ao risco de disseminação de microrganismos para o paciente, ocasionado pelo não uso desse EPI. 
Os achados desta pesquisa são concordantes com outros trabalhos que apontam que o uso do EPI na assistência de enfermagem ainda é uma dificuldade encontrada em diversos serviços ${ }^{26-28}$, pois estes são vistos apenas como equipamento de autoproteção e podem funcionar como vetor de disseminação de microrganismos devido ao seu mau uso e compartilhamento entre pacientes ${ }^{27}$. Ademais, há uma escassez na literatura que apontam a funcionalidade dos EPI na redução das taxas de infecção.

Em relação aos curativos de CVC, estes possuem o propósito de proteger o sítio de punção, minimizar as possibilidades de infecção e prevenir a movimentação do dispositivo com dano ao vaso. As coberturas utilizadas devem ser estéreis, podendo variar entre gaze e fita adesiva estéril (semioclusivo) e membrana transparente semipermeável (oclusivo) ${ }^{20}$.

Estudos ${ }^{29-32}$ compararam a utilização da membrana transparente semipermeável e a gaze estéril, porém não encontraram diferença estatisticamente significativa entre a utilização desses dois tipos de coberturas e a redução de ICSRC, porém essa comparação não foi estudada nesta pesquisa. Outros estudos apontam que a membrana transparente semipermeável apresenta a vantagem de adaptabilidade aos contornos do corpo, visualização e monitoração direta do cateter vascular, ação como barreira à contaminação da ferida, impermeabilidade à água e a outros agentes e troca em período maior de tempo (sete dias), diminuindo assim, sua manipulação e, consequentemente, menor risco de infecção ${ }^{31}$. Estudos trazem resultados similares aos encontrados nesta pesquisa, que utilizou membrana transparente semipermeável em aproximadamente $60 \%$ dos pacientes.

Recomenda-se usar gaze e fita adesiva estéril apenas quando a previsão de uso do cateter seja menor do que 48 horas (III) e em caso de sangramento ou diaforese excessivos ${ }^{20}$. É imprescindível a troca da cobertura se, independente do prazo, esta estiver suja ou solta (II) ${ }^{20}$.

Ademais, o curativo tem a função de fixar o CVC no sítio de inserção, com o objetivo de preservar a sua integridade, prevenir seu deslocamento e sua perda. A estabilização deve ser feita utilizando técnica asséptica e não devem ser utilizadas fitas adesivas não estéreis, que podem ser facilmente contaminadas com microorganismos patogênicos, e suturas (III), pois estas estão associadas a acidentes percutâneos, favorecem a formação de biofilme e aumentam o risco de infecção primária de corrente sanguínea (IPCS) ${ }^{20,33-34}$. Apesar dessas informações, não existem estudos com sugestões de melhores métodos de fixação de CVC, sendo um tema que ainda precisa ser muito discutido pela literatura.

A limpeza do sítio de inserção do CVC utilizando solução de gluconato de clorexidina degermante a $2 \%$ e da solução alcoólica a $0,5 \%$ é indicada por diversos estudos (I) ${ }^{20,35-38}$ devido seu comportamento como agente microbicida, cuja ação em baixas concentrações é bacteriostática, mas que em concentrações elevadas tem uma rápida ação bactericida ${ }^{35}$.

A técnica asséptica utilizada pelos enfermeiros foi inadequada em $100 \%$ dos curativos desta pesquisa. Recomenda-se que o tempo de aplicação da clorexidina alcoólica seja de 30 segundos e deva ser realizada por meio de 
movimentos de vai e vem, com gaze trocada de lado a cada pincelada (III) ${ }^{20}$, aguardando a secagem espontânea do antisséptico antes da continuação do procedimento. Além disso, a degermação da pele com clorexidina degermante não é recomendada rotineiramente, estando reservado para casos onde exista sujidade visível ${ }^{20,35}$, o que não foi observada na realização desta pesquisa. Problema encontrado na realização do curativo foi à indisponibilidade da solução de gluconato de clorexidina a $0,5 \%$ no campo de estudo durante a realização da pesquisa.

Os cuidados com os CVC são de inteira responsabilidade dos enfermeiros, que exercem papel fundamental na manutenção e na retirada do cateter. Pode-se citar como cuidados de enfermagem a higienização das mãos, a avaliação do sítio do cateter, a desinfecção dos conectores do CVC, preparo e administração de medicamento se a troca do sistema de infusão ${ }^{39}$.

A higienização das mãos é considerada o cuidado de enfermagem mais importante na prevenção de IRAS e a falta de adesão a essa prática é uma realidade que vem sendo constatada, devendo ser estimulada e conscientizada entre os profissionais ${ }^{40-41}$.

Os resultados desta pesquisa são concordantes com outros estudos ${ }^{28,29}$ que apontam a baixa adesão à higienização das mãos entre profissionais da saúde. Nesta pesquisa, a taxa de enfermeiros que higienizaram as mãos antes da realização do curativo foi de $40 \%$, enquanto os que higienizaram após a realização do curativo foi maior $(73,3 \%)$, sendo considerada higienização das mãos o uso de água e sabão e/ou o uso de solução alcoólica. Em um trabalho realizado em Ribeirão Preto ${ }^{41}$ apenas $35,4 \%$ dos profissionais da saúde empregaram a técnica da lavagem das mãos e somente 3,7\% fizeram referência à higienização das mãos com solução alcoólica, o que alerta para um índice importante, pois a higienização das mãos deve ter representatividade próxima de 100\% por ser uma medida básica e essencial.

Estudos ${ }^{27,41-42}$ demonstram que a não adesão à higienização das mãos não está diretamente associada ao conhecimento teórico do ato da higienização ou da situação em que se deve realizá-la, mas sim a incorporação desse conhecimento à prática diária dos profissionais em que se observa: falta de motivação, não concepção do risco de disseminação de microrganismos, excesso de atividades/tarefas e falta de materiais e/ou deficiência da estrutura física da instituição.

A higienização das mãos deve ocorrer em qualquer tipo de manipulação do cateter (II), sendo usados água e sabonete líquido, quando estiverem visivelmente sujas ou contaminadas com sangue e outros fluídos corporais, ou usar preparação alcoólica (60 a 80\%) para quando as mesmas não estiverem visivelmente sujas. No cuidado específico com CVC, a higienização das mãos deverá ser realizada antes e após tocar o sítio de inserção do cateter, bem como antes e após a inserção, remoção, manipulação ou troca de curativo. É importante ressaltar que o uso de luvas não substitui a necessidade de higiene das mãos ${ }^{20}$. 
Na finalização do processo de cuidar do paciente portador de CVC é importante ressaltar as anotações dos cuidados de enfermagem no prontuário. Nesta pesquisa, apenas $4(26,6 \%)$ enfermeiros anotaram sobre o procedimento de troca do curativo de CVC e a presença ou não de sinais flogísticos do sítio de inserção. A evolução de enfermagem é imprescindível, pois possibilita o planejamento da assistência, reflete a produtividade da equipe, faturamento do procedimento e é fonte de consulta para auditorias de enfermagem e comprovam a jornada de trabalho. A evolução dos sinais flogísticos no prontuário serve de alerta para os demais profissionais da saúde que tiverem acesso ao documento, possibilitando ações em prol da melhoria da assistência ao paciente ${ }^{15}$.

\section{CONCLUSÃO}

A presente pesquisa permitiu avaliar os cuidados de enfermagem relacionados à troca de curativo do CVC, comparar a conduta dos enfermeiros ao protocolo padronizado na instituição e analisar os resultados baseando-se no manual da ANVISA "Medidas de Prevenção de Infecção Relacionada à Assistência à Saúde" de 2017.

Durante a realização da reunião para subsídios de melhorias com os enfermeiros, ficou evidente, através de discussões e sugestões, que estes estão interessados em melhorar os resultados encontrados nesta pesquisa. Além disso, foi proposto uma atualização do protocolo da instituição, favorecendo melhorias nos cuidados de enfermagem ao paciente portador de CVC.

Os benefícios encontrados após esta auditoria foram o enaltecimento da participação do enfermeiro como agente minimizador dos riscos relacionados à ICSRC, rememoração da responsabilidade pela manutenção da qualidade assistencial para o paciente e incentivo ao uso de evidências científicas para as tomadas de decisões.

Ressaltam-se limitações do estudo, por se restringir ao espaço das vivências dos sujeitos envolvidos. Com isso, não é possível realizar generalizações do seu conteúdo para outras equipes de enfermeiros.

A auditoria no cuidado de enfermagem na troca de curativo de CVC favoreceu um processo educativo entre os enfermeiros, no qual não se buscou os responsáveis pela falha, mas questionou-se o porquê da não conformidade. Além disso, contribuiu para identificar estratégias para melhorar a assistência de enfermagem, no intuito de oferecer um cuidado seguro e de qualidade.

\section{REFERÊNCIAS}

1. Couto RC, Pedrosa TMG, Franca A. Infecção hospitalar e outras complicações não-infecciosas da doença: epidemiologia, controle e tratamento. Rio de Janeiro: Guanabara Koogan; 2009. 
2. Spir PRN. Epidemiologia das infecções de corrente sanguínea de origem hospitalar em hospital de assistência terciária. (Dissertação de Mestrado). São Paulo: Faculdade de Medicina da Universidade de São Paulo; 2007.

3. Agência Nacional de Vigilância Sanitária. Orientações para a prevenção de infecção primária de corrente sanguínea. Brasília: ANVISA; 2010.

4. Bonvento M. Acessos vasculares e infecções relacionadas a cateter. Rev. bras. ter. intensiva. 2007;19(2):1-5.DOI:10.1590/S0103507X2007000200015.

5. Koutzavekiaris I, Vouloumanou EK, Gourni M, Rafailidis PI, Michalopoulos A, Falagas ME. Knowledge and practices regarding prevention of infections associated with central venous catheters: A survey of intensive care unit medical and nursing staff. Am. J. Infect. Control. 2011;39(7):542-47. DOI: 10.1016/j.ajic.2010.11.003.

6. Santos ER, Leal R, Cavalheiro AM. Cateter venoso central. Knobel E. Terapia Intensiva: Enfermagem. São Paulo: Atheneu; 2006. p.189-196.

7. Rosado V; Romanelli RM; Camargos PA. Risk factors and preventive measures for catheter-related bloodstream infections. J Pediatr (Rio J). 2011;87(6):469-77.DOI:10.2223/JPED.2134.

8. Centers for Disease Control and Prevention. Definition of health care associated infection and criteria for specific types of infections. USA: CDC; 2002.

9. Pereira JC. Notificação de infecção em corrente sanguínea associada a cateter venoso central (CVC) - uma comparação dos critérios do National Healhcare Safety Network (NHSN) e da Agência Nacional de Vigilância Sanitária (ANVISA). (Especialização). Belo Horizonte: Universidade Federal de Minas Gerais, 2011.

10. Pierotto, AAS. Infecção de corrente sanguínea relacionada ao uso de cateteres venosos centrais em pacientes pediátricos de um hospital terciário. (Dissertação de Mestrado). Porto Alegre: Pontifícia Universidade Católica do Rio Grande do Sul; 2015.

11. Mendonça KM, Neves HCC, Barbosa DFS, Souza ACS, Tipple AFV, Prado MA. Atuação da enfermagem na prevenção e controle de infecção de corrente sanguínea relacionada a cateter. Rev. Enferm. UERJ, 2011;19(2)330-3.

12. Giarola LB, Baratieri T, Costa AM, Bedendo J, Marcon SS, Waidman MAP. Infecção hospitalar na perspectiva dos profissionais de enfermagem: um estudo bibliográfico. Cogitare Enfermagem [Internet]. 2012;17(1):151-157. Disponível em: http://www.redalyc.org/articulo.oa?id=483648962022

13. Brasil. Decreto n.o 8932, de 14 de dezembro de 2016. Aprova o Estatuto e o Quadro Demonstrativo dos Cargos em Comissão e das Funções de Confiança da Fundação Oswaldo Cruz - FIOCRUZ, 
remaneja cargos em comissão e funções de confiança, substitui cargos em comissão do Grupo Direção e Assessoramento Superiores - DAS por Funções Comissionadas do Poder Executivo - FCPE. Diário Oficial da União, 14 dez 2016.

14. Rosa LA, Caetano LA, Matos SS, Reis DC. Auditoria como estratégia de avaliação dos registros de enfermagem em unidade de internação pediátrica. Reme - Rev. Min. Enferm. 2012;16(4):546-5543.

DOI:S141527622012000400010

15. Oliveira Jr NJ, Cardoso KE. O papel do enfermeiro frente à auditoria hospitalar. Rev. Adm. Saúde. 2017;17(68):1-15. DOI: 10.23973/ras.68.52

16. Canadian Task Force on Preventive Health Care website. GRADE. [Acesso em 10 nov. 2017]. Disponível em:

http://canadiantaskforce.ca/methods/grade/.

17. Guyatt $\mathrm{GH}$, Oxman AD, Vist GE et al. GRADE: an emerging consensus on rating quality of evidence and strength of recommendations. BMJ 2008;336:924-6.

18. Rosado V. Incidência e Complicações Infecciosas Associadas ao uso de cateteres venosos centrais em população pediátrica de um hospital universitário. (Dissertação de Mestrado). Belo Horizonte: Faculdade de Medicina da Universidade Federal de Minas Gerais; 2012.

19. Torquato APA, Oliveira SLCB, Sarat CNF. Infecção relacionada ao cateter venoso central em unidades de terapia intensiva. Ensaios e Ciência: Ciências Biológicas, Agrárias e da Saúde. 2012;16(1):25-41

20. Agência Nacional de Vigilância Sanitária. Medidas de Prevenção de Infecção Relacionada à Assistência à Saúde. Brasília: ANVISA; 2017.

21.Perin DC, Erdmann AL, Higashi GDC, Sasso GTM. Evidências de cuidado para prevenção de infecção de corrente sanguínea relacionada a cateter venoso central: revisão sistemática. Rev.Latino-Am.Enfermagem. 2016;24:e2787. DOI: 10.1590/1518-8345.1233.2787.

22. Merrer J, De Jonhghe B, Golliot F, Lefrant J, Raffy B, Barre E, et al. Complications of femoral and subclavian venous catheterization in critically ill patients. JAMA 2001 August; 286(6):700-7.

23. Petrini CA, Marino LO. Acesso Venoso Guiado por Ultrassonografia. Martins HS, Neto RAB, Neto AS, Velasco IT. Emergências Clínicas: Abordagem Prática. São Paulo: Manole; 2015. p.131-141

24. Eyer S, Brummitt C, Crossley K, Siegel R, Cerra F. Catheter-related sepsis: prospective, randomized study of three methods of long-term catheter maintenance. Crit Care Med 1990; 18:1073-9. 133. 
25. Cobb DK, High KP, Sawyer RG et al. A controlled trial of scheduled replacement of central venous and pulmonary-artery catheters. $\mathrm{N} \mathrm{Engl} \mathrm{J}$ Med 1992; 327:1062-8. 134

26. Rodríguez IC, Lemus MAB, Crehuet MR, Briso-Montiano PM, López CR. Bioconectores: ¿Son realmente eficaces en la reducción de las bacteriemias relacionadas con el catéter permanente para hemodiálisis? Enferm Nefrol. 2013;16(4):235-40.

27. Oliveira AC, Cardoso CS, Mascarenhas D. Precauções de contato em Unidade de Terapia Intensiva: fatores facilitadores e dificultadores para adesão dos profissionais. Rev. Esc. Enferm. USP. 2010; 44(1):161-165. DOI: 10.1590/S0080-62342010000100023

28. Tomaz VS, Neto FHC, Almeida PC, Maia RCF, Monteiro WMS, Chaves EMC. Medidas de prevenção e controle de infecções neonatais: opinião da equipe de enfermagem. Rev Rene. 2011; 12(2):271-8.

29. Santos SF, Viana RS, Alcoforado CLGC, Campos CC, Matos SS, Ercole FF. Ações de enfermagem na prevenção de infecções relacionadas ao cateter venoso central:uma revisão integrativa. Rev. SOBECC. 2014; 19(4): 219225. DOI: $10.5327 / Z 1414-4425201400040008$

30.Webster J, Gillies D, O’Riordan E, Sherriff KL, Rickard CM. Gauze and tape and transparent polyurethane dressings for central venous catheters. Cochrane Database System Rev. 2011;9(11):CD003827.

31. Andrade AM, Borges KS, Lima HO. A avaliação das coberturas para sítio de inserção do cateter venoso central no TMO: análise de custos. ver Min Enferm. 2011;15(2):233-41.

32. Vandijck DM, Labeau SO, Secanell M, Rello J, Blot SI. The role of nurses working in emergency and critical care environments in the prevention of intravascular catheter-related bloodstream infections. Int Emerg Nurs. 2009;17(1):60-8.

33. Lalayanni C, Baliakas $P$, Xochelli A et al. Outbreak of cutaneous zygomycosis associated with the use of adhesive tape in haematology patients. J Hosp Infect 2012; 81:213-5.

34. Goski L, Hadaway L, Hagle ME, McGoldrick M, Orr M, Doellman D. Infusion teraphy standards of practice. J Infus Nurs 2016;39(suppl1):S1- S159

35. Mimoz O, Lucet JC, Kerforne T, et al. Skin antisepsis with chlorhexidinealcohol versus povidone iodine-alcohol, with and without skin scrubbing, for prevention of intravascular-catheter-related infection (CLEAN): an open-label, multicentre, randomised, controlled, two-by-two factorial trial. Lancet. 2015 Nov 21;386(10008):2069-77.

36. Marschall J, Mermel LA, Fakih M, et al. Strategies to Prevent Central LineAssociated Bloodstream Infections in Acute Care Hospitals: 2014 Update Infect Control HospEpidemiol 2014;35 Suppl 2:S89-107 
37. O'Grady NP, Alexander M, Burns LA et al. Guidelines for the prevention of intravascular catheter-related infections. Am J Infect Control 2011;39(4 Suppl 1):S1-34

38. Simmons S, Bryson C, Porter S, "scrub the hub": cleaning duration and reduction in bacterial load on central venous catheters. Crit Care Nurs $Q$ $2011 ; 34: 31-5$.

39. Murakami BM, Santos EB. Enfermagem em Terapia Intensiva. São Paulo: Atheneu; 2015.

40. Agência Nacional de Vigilância Sanitária. Higienização das mãos em serviços de saúde. Brasília: ANVISA; 2007.

41. Moura JP. A Adesão dos profissionais de enfermagem às precauções de isolamento na assistência aos portadores de microrganismos multirresistentes (dissertação de mestrado). Ribeirão Preto: Escola de enfermagem de Ribeirão Preto, Universidade de São Paulo; 2004.

42. Muto C, Jernigan JA, Ostrowsky BE, Richei HM, Jarvis WR, Boyce JM et al. SHEA Guideline for Preventing Nosocomial Transmission of MultidrugResistant Strains of Staphylococcus aureus and Enterococcus. Infect Control Hosp Epidemiol. 2003;24(5):362-86.

Recebido: 24 de fevereiro de 2018. Publicado: 14 de março de 2018

Correspondência: Fernanda Coura Sousa. E-mail:

fernandacouraps@gmail.com

Conflito de Interesses: os autores da pesquisa declaram que não possuem conflito de interesse pessoal, comercial, acadêmico, político ou financeiro.

(C) This is an Open Access article distributed under the terms of the Creative Commons Attribution License, which permits unrestricted use, distribution, and reproduction in any medium, provided the original work is properly cited 